\title{
DO INSTITUTO INTERNACIONAL DE BIBLIOGRAFIA AO INSTITUTO BRASILEIRO DE BIBLIOGRAFIA E DOCUMENTAÇÃO: AS BIBLIOGRAFIAS COMO MEMÓRIA DO CONHECIMENTO E REFLEXOS DAS IDEIAS DE OTLET NO BRASIL
}

\author{
DEL INSTITUTO INTERNACIONAL DE \\ BIBLIOGRAFÍA AL INSTITUTO BRASILEÑO DE \\ BIBLIOGRAFÍA Y DOCUMENTACIÓN: \\ LAS BILBIOGRAFÍAS COMO MEMÓRIA DE \\ CONOCIMIENTO Y REFLEJOS DE LAS IDEAS DE \\ OTLET EN BRASIL
}

\begin{abstract}
Lena Vania Ribeiro Pinheiro - lenavania@ibict.br Doutora em Comunicação e Cultura pela Universidade Federal do Rio de Janeiro (UFRJ). Pesquisadora do Instituto Brasileiro de Informação em Ciência e Tecnologia (IBICT).
\end{abstract}

\begin{abstract}
RESUMO
Introdução: $O$ trabalho investiga os primeiros conceitos de bibliografia formulados por documentalistas históricos, a concepção de bibliografias como "método científico de prospecção e classificação" e a distinção entre a concepção de uma classificação e o ato de classificar, e dificuldades de tradução (classement, classer e classification).

Objetivo: Discutir a relação entre bibliografia e repertório e os atuais repositórios.

Metodologia: Trata-se de um trabalho teórico, estruturado em a partir de pesquisa bibliográfica.

Resultados: percebe as bibliografias como memória do conhecimento e em diferentes abordagens relacionadas às atividades em bibliotecas: memória mensagem, memória coletiva tradicional, memória cognitiva, memória cultural livresca, memória diálogo e memória vivida, entre outras.

Conclusões: relaciona os reflexos das bibliografias e ideias de Paul Otlet nas ações de informação contemporâneas, especialmente no Brasil: o Instituto Brasileiro de Bibliografia e Documentação hoje IBICT- Instituto Brasileiro de Informação em Ciência e Tecnologia, o Curso de Pesquisas Bibliográficas, publicações, estudos e pesquisas brasileiros.
\end{abstract}


Palavras-chave: Bibliografia. Conceitos de bibliografia. Bibliografia e memória. Paul Otlet e sua influência no Brasil.

\section{ALGUNS ASPECTOS HISTÓRICOS, CONCEITUAIS E TÉORICOS DA BIBLIOGRAFIA}

As observações iniciais deste artigo, originalmente uma palestra, estão mais relacionadas ao estudo dos aspectos históricos, conceituais e teóricos da bibliografia, a fim de compreender esse documento a partir de suas funções originais e para além de sua aplicação e utilidade, nas suas transmutações no tempo - um documento de memória do conhecimento, lato sensu.

Embora historicamente a primeira bibliografia seja a de Conrad Gesner $^{1}$ naturalista suíço que reuniu, na Bibliotheca Universalis, obras nas línguas latina, grega e hebraica, publicadas entre 1545 a 1549, foi na França que as bibliografias ganharam espaço nos estudos documentais, inicialmente com Louise Noelle Malchès (1899-1977)2, professora e bibliotecária da Sorbonne.

A definição de bibliografia, por Malclès, abrange:

[...] o conhecimento de todos os textos impressos ou multigrafados. Fundamenta-se na pesquisa, na identificação, descrição e classificação de documentos, a fim de organizar serviços ou construir instrumentos destinados a facilitar o trabalho intelectual (apud BRIET, 1951, p.8).

\footnotetext{
${ }^{1}$ A grafia do nome aparece de diferentes formas e optamos por adotar a que é mais comumente utilizada na literatura da área- Conrad Gesner.

${ }^{2}$ MALCLĖS, Louise Noelle. La bibliographie. Paris: P.U.F., 1973. 128p. Coll Que sais-je?, no. 708.
} 
Ainda segundo a mesma autora, a "técnica ou ciência bibliográfica" resulta de repertórios denominados bibliográficos, sendo constituída das quatro operações sucessivas mencionadas na definição. Aqui, Malclès, na dúvida entre técnica ou ciência bibliográfica, vislumbra a perspectiva da bibliografia ser mais do que uma técnica. Embora não se constitua em uma ciência, surge como uma disciplina da Documentação e hoje assim é na Biblioteconomia, papel que o presente evento resgata e reconhece, na sua relevância.

Quem cita Malclès é a documentalista francesa, Suzanne Briet (1951, p. 8) que, quando escreve sobre bibliografia, considera a "abundância de documentos escritos" e reconhece a necessidade, no século XVII, de "um método científico de prospecção e de classificação (classement) de livros e manuscritos". Ao buscar um método científico, a autora demonstra o que representa para ela uma bibliografia, além da capacidade de prospecção desse documento. Chama a atenção a atribuição da possibilidade de prospecção, termo incomum à época, mas hoje muito utilizado na Ciência da Informação para a prospecção de informações em P\&D ou de cadeias produtivas, com fins de orientação ao futuro.

Por outro lado, Briet (1951, p. 8) acredita ser importante assinalar as diferenças entre uma bibliografia teórica "que estabelece as regras de pesquisa e de classificação", e a bibliografia prática, "que aplica essas regras para a elaboração de instrumentos de pesquisa que são as bibliografias". Acredito que a distinção entre os dois tipos de bibliografia, a teórica e a prática, possa ser correlacionada à diferença entre "classification" e "classement", a primeira relativa à concepção teórica de uma classificação e, a segunda, à inserção do documento em uma classe. 
No livro "La documentation au service de l'action", Guinchat e Aubret (1977, p. 122) apresentam ao final um léxico, do qual constam as definições de classement, classer e classification ${ }^{3}$. A primeira seria "a operação que consiste em grupar os documentos em classes adequadas"; classer corresponderia à ação "encarregada pelo trabalho material de inserir em classes (classement)" e, o último, classificação (classification), refere-se à "operação intelectual destinada a estabelecer classes em um plano lógico, hierarquizado ou não". Os autores admitem que classificação é também resultado dessa operação, o que pode confundir as diferenciações, sobretudo em língua portuguesa, na qual não constam.

Sobre os aspectos teóricos, Egan e Shera (1952), em artigo discutindo a questão, ressaltam o conflito de duas visões sobre bibliografia, uma como método macroscópico, que chamaremos de social, e outra microscópica, compreendida por nós como funcionalista. Na primeira, a bibliografia é vista como "instrumento de comunicação e a comunicação em si como instrumento de organização e ação social" e, na segunda, microscópica, como um instrumento separado para "atender a necessidades específicas de um número limitado de pessoas, com mais ou menos interesses comuns". Nesse caso, não haveria relação entre as bibliografias, independentes umas das outras, e o "fluxo total de comunicação".

É este o enfoque que permeia o conteúdo do presente artigo - o de um duplo papel da bibliografia ou de duas linhas de pensamento.

\footnotetext{
${ }^{3}$ Sobre as denominações adotadas por Suzanne Briet, a Professora Hagar Espanha Gomes em comunicação informal confirmou as distinções e mencionou Antonio Houaiss, que abordou o assunto, provavelmente na sua obra 'Elementos de bibliologia', até chegando a propor o verbo "classear" para "classer/ classement", distinto de classificar.
} 


\section{DOS REPERTÓRIOS AOS REPOSITÓRIOS}

Para as grandes bibliotecas, outros instrumentos são os catálogos, de três tipos: correntes, retrospectivos e coletivos, considerados por Briet (1951, p.8), ferramentas obrigatórias, de "grau secundário" e intermediárias entre os documentos e usuários. Entendase de grau secundário as chamadas publicações secundárias, além dos catálogos, as bibliografias, índices, resumos, bases de dados e, modernamente, as bibliotecas digitais e repositórios, por exemplo. Esses produtos de informação são criados para responder às mesmas funções das bibliografias, ampliadas, na medida dos recursos da Internet e de novos movimentos na Ciência da Informação, aliados à mudança de paradigmas comunicacionais e de informação da Ciência e sua repercussão em nossa área, como o acesso livre à informação científica, um dos temas mais caros à Ciência da Informação, atualmente.

O famoso Repertório Bibliográfico Universal de Paul Otlet foi concebido como uma soma de diferentes bibliografias, semelhante a um catálogo, "no qual deve ser registrada integralmente e classificada toda a produção intelectual, de forma a constituir um inventário e que se torne amplamente acessível a todos os fins" Um repertório abrangeria "as obras e todos os escritos de todos os tempos, produtos de todos os países, sob todas as formas, de todas as áreas". Apesar da amplitude de seu conteúdo, não incluiria "a música, as gravuras, a numismática, a epigrafia e as peças de arquivos" (OTLET, 1934, p.404).

No entanto, cabe esclarecer que não se trata de exclusão desses objetos como documentos, já que Otlet os estuda, ao lado de documentos mais tradicionais como livros, tratados, enciclopédias. Estes são por ele denominados "documentos gráficos", entre os quais manuscritos; mapas, planos, atlas; os iconográficos, por exemplo, gravuras e fotografias; cartões postais e fotografias; arquivos; música e "monumentos ditos figurados, tais como inscrições, moedas e medalhas." Cada um desses tipos de documentos constituem 
subcapítulos de seu livro, reunidos no capítulo 242, denominado "documentos gráficos outros que não as obras impressas." (OTLET, 1934, p.183-226).

Deve-se acrescentar, na miríade de documentos estudados por Otlet e sob o seu olhar acolhedor do novo, aqueles que ele considerou "invenções maravilhosas" e "substitutos do livro", por entender que, embora não fossem prolongamento direto dos livros, seriam uma espécie de "prolongamento desviado" do seu curso original: os objetos de museus, o telégrafo, o telefone, o rádio, a televisão, o cinema e os discos, que "estenderiam imensamente as possibilidades da Documentação".

A concepção de repertório por Otlet, configura a sua abordagem social e democrática, já que os considera no todo, sem especificar pessoas ou grupos, constituindo memória do conhecimento universal e disponível para a sociedade.

Entre os repertórios de Otlet e os repositórios contemporâneos, mais de um século e meio os separam, e a semelhança não decorre apenas da grafia das duas palavras. O surgimento dos repositórios se deve à crise dos periódicos científicos, cujos custos praticamente inviabilizaram a compra de assinaturas por entidades como bibliotecas e mesmo os próprios pesquisadores /autores. Outra causa foi a disponibilidade de tecnologias de informação e comunicação, por meio do Open Archives (OA), que "estabelece um conjunto de padrões com vistas à interoperabilidade entre os repositórios digitais" (KURAMOTO, 2006, p. 93 apud CHALHUB, 2012). Por outro lado, não era justo que pesquisas financiadas pelo governo, portanto, com dinheiro público, não pudessem ser usufruídas pelos autores e suas respectivas instituições. Assim, um novo paradigma para a comunicação científica vem responder a esse conflito de interesses - o acesso livre / aberto à informação científica, 
$\mathrm{Na}$ sua essência, os repositórios representam o conhecimento científico de uma área, de uma instituição e, mais recentemente, de dados científicos de pesquisa.

Para Crow (2002 apud CHALHUB, 2012) o repositório institucional:

[...] concentra a produção intelectual dos pesquisadores da universidade, sendo uma clara demonstração de seu valor científico, educacional, social e econômico. [...] Aumentando a visibilidade reflete a alta qualidade da universidade, demonstrando o valor que pode ser traduzido em benefícios tangíveis, incluindo financiamento - de recursos públicos e privados.

Já os repositórios temáticos abrangeriam a produção científica em um determinado campo do conhecimento, subárea ou disciplina.

Para explicitar o que são os repositórios de dados científicos recorremos a Sayão e Sales (2013, p.7), em artigo no qual estabelecem a diferença entre dados intermediários e dados finais de pesquisas. Os primeiros representam os chamados dados científicos, isto é, aqueles que são obtidos no processo preliminar de pesquisa e, "com muita frequência, não são arquivados ou permanecem inacessíveis para outros pesquisadores".

Esses dados não são incluídos quando a pesquisa é publicada sob a forma de artigo, capítulo de livro ou outro documento, o que representa uma lacuna e restrição muito grande para pesquisadores que posteriormente estudem as mesmas questões, sem poder usufruir desses dados. Hoje, com as tecnologias de informação e comunicação, é possível incorporá-los no que vem sendo denominado "publicações ampliadas" (enhanced publication).

A visão de documentos como herança universal, reunindo os conhecimentos gerados em múltiplos países, sociedades e momentos, disponibilizados sob diferentes formas documentais à sociedade, hoje 
sob a égide do acesso livre à informação científica, nos leva a pensar as bibliografias como memória do conhecimento.

\section{AS BIBLIOGRAFIAS COMO MEMÓRIA DO CONHECIMENTO}

Quando Briet (1951, p.8) fala na intensidade de publicações após Guttenberg, observa que a partir daí surge o problema da utilização de documentos gráficos e de sua conservação. Ora, se a bibliografia representa a reunião do conhecimento gerado no mundo e, consequentemente, de sua conservação, aí estão imbricadas questões de memória científica e técnica.

Diferentes autores estudaram a memória, em distintas abordagens: memória coletiva, memória mensagem, memória administrativa, memória seletiva, narrativa, crônicas, comemorações, sob a ótica de áreas como a Sociologia, a Antropologia e a História. Há, no entanto, um autor nucleador de ideias, Halbwachs (1990), marco entre aqueles que pesquisaram questões relativas à memória, sem cujos estudos saberíamos muito menos acerca desse tema, sobretudo memória coletiva. Profundamente influenciado pelos historiadores sociologiantes como Marc Bloch e Lucien Febvre, Halbwachs (1990) foi um continuador das ideias de Durkheim, com as quais mais se afinava, o que está patente na sua obra "Os quadros sociais da memória". Neste tópico nos interessa o conceito de memória mais diretamente relacionado à memória de instituições como bibliotecas, centros de documentação e informação.

É fundamental assinalar que a memória, ao longo dos séculos, teve funções e papéis diferentes, o que se acentuou na passagem das sociedades sem escrita para aquelas com escrita, o que está relacionado à diferenciação de contextos e às formas de comunicação. Alguns autores escreveram sobre o tema e são incluídos neste estudo especialmente dois: Foskett (1973) e Borges (1985), o primeiro na 
Ciência da Informação e Borges, embora da literatura, por suas ideias sobre livros e memória.

É preciso não esquecer que a memória foi uma questão sempre presente entre as preocupações dos homens, desde os gregos antigos e sua filosofia. Em dois textos, Platão aborda o assunto - Fedro e Teeteto. No primeiro assinala os malefícios da escrita, culpada de levar o homem a uma "ausência de exercício de memória", por "enamoramento do devir" (apud VERNANT,1973).

A tradição oral na antiguidade clássica explica a introdução dessa questão por Foskett (1973, p.3) que, ao escrever sobre "alguns aspectos sociológicos dos sistemas formais de comunicação", traça um histórico dessa transmissão. Ele inicia o seu artigo, oriundo de uma conferência, reproduzindo um bilhete de Alexandre a seu preceptor, Aristóteles, que bem exemplifica essa associação de saber e poder: "De Alexandre para Aristóteles: Saudações. Não fizeste bem em publicar tuas obras de doutrina; pois, em que nos diferenciamos agora dos outros, se as ciências em que nos instruíste serão comuns a todos?".

O escritor Borges (1985) lembra o quanto a palavra oral norteava a comunicação na Grécia antiga. Muitos filósofos nada deixaram de escrito e são conhecidos apenas por meio de seus discípulos ou por doxografia. Como ressaltamos, era tradição a palavra oral, daí o culto à oratória e, mais do que isso, a sua sacralidade. Para Platão (apud BORGES, 1985), a palavra oral era "fugaz e sagrada", o que não significa exatamente efêmera, a palavra escrita é que continha "algo duradouro e morto". Os gregos da antiguidade deliberadamente não escreveram porque assim pensavam.

Borges (1985), ao falar de livros enfoca a memória, reconhecendo que temos "necessidade de um exercício que nos renove incessantemente a memória daquilo que conhecemos".

Não foi somente sob esse aspecto que a oralidade se tornou uma forma escolhida de comunicação, mas também a elitização ou 
politização do conhecimento, mesmo registrado, concentrado que esteve, por séculos, nas mãos de governantes, reis e sacerdotes. Hoje, os canais informais, tão estudados na comunicação científica, mostram o quanto a comunicação oral é relevante, por conduzir informações mais novas, correntes.

O conhecimento e a informação desde então eram, claramente, questão de poder, e sua democratização viria séculos, milênios depois.

No capítulo de seu livro em que aborda a memória coletiva e a memória histórica, Halbwachs (1990) enfoca essa dupla memória humana: individual (memória autobiográfica, pessoal) e coletiva, a segunda mais ampla e, por isso, abrangendo a primeira sem, contudo, com essa se confundir. Portanto, não há memória individual sem a coletiva, esta última é que lhe dá sentido. A memória é sempre coletiva, de grupos sociais, memória social. Sobre a memória histórica Halbwachs (1990, p.80) reconhece que esse termo é inadequado e incoerente porque, na sua concepção, "memória coletiva não se confunde com a história", que é "a compilação dos fatos que ocuparam o maior espaço na memória dos homens". É o que se escreveu sobre o que passou, uma espécie de "ponte entre o passado e o presente [...]".

Outra distinção por ele destacada é sobre a memória coletiva como "uma corrente de pensamento contínuo, de uma continuidade que nada tem de artificial, já que retém do passado somente aquilo que ainda está vivo ou capaz de viver na consciência do grupo que a mantém" (HALBWACHS, 1990, p. 82).

No prefácio do livro póstumo de Halbwachs, sobre "A memória coletiva", Duvignaud (1990, p. 11) conclui que Halbwachs abre espaço, na França, para "alguns conceitos operatórios novos" de memória e que o seu pensamento, em memória coletiva, ultrapassa a sociologia clássica e faz um caminho inverso, dentro de uma nova vocação, "não mais tentando saber por que, no meio da trama coletiva da existência, surge e se impõe a individuação [...]" (DUVIGNAUD, 1990, p.17). 


\subsection{As bibliografias como Instrumentos de Memória do Conhecimento}

É Gerard NAMER (1987) quem, no capítulo "Les institutions de mémoire culturelle", da obra "Memória e sociedade", estuda as instituições de memória cultural, especialmente as bibliotecas.

O seu ponto de partida foi a "construção social da memória individual", que o levou a ideia de que há uma " totalização de lembranças dentro de um modelo, até a atualização desta memória, de virtual à reconstruída, atualizada" (NAMER, 1987, p.160). Se, para ele, há inúmeros "lugares de memória (de memória individual, social ou coletiva), os lugares de uma determinada memória social são reduzidos - instituições de memória cultural" e são aqueles que nos interessam particularmente, no caso, os produtos gerados no seu espaço, como bibliografias, repertórios e hoje bibliotecas digitais e repositórios

Namer (1987, p.159) busca um modelo de instituição de memória, primeiramente para a biblioteca e, em uma segunda etapa, o estende aos museus. Na sua concepção, "a biblioteca organiza, de forma regulamentar, uma prática particular de memória cultural, aquela que implica na leitura". Assim, a biblioteca é, em princípio, uma instituição de memória cultural de sociedades com escrita, letradas, eruditas, uma espécie de memória do mundo", na qual o livro é "memória virtual que se atualiza pela leitura dentro de uma sala de trabalho [...] uma memória social, resultado da circulação e interação de memória coletivas". A biblioteca "herda uma superposição de vontades coletivas, instituições, de memórias" sendo, consequentemente, "memória cumulativa de saber e de cultura" (NAMER 1987, p.161).

No decorrer de seu estudo, Namer (1987) identifica formas de memória em atividades realizadas nas bibliotecas: memória mensagem, memória coletiva tradicional, memória cognitiva, memória cultural livresca, memória diálogo, memória vivida etc., cada uma com suas respectivas explicitações. Por analogia, podemos entender as 
bibliografias como memória cognitiva, memória cultural livresca, entre outras.

As formas de memória que habitam a biblioteca foram se modificando através dos tempos, podendo ser demarcadas algumas fases.

As primeiras, existentes na Assíria no terceiro milênio a.C. correspondem à memória do saber econômico, relativo à propriedade e aos impostos. É o saber das e para as elites do poder, denominado "saber esotérico do poder". Nessa fase, a biblioteca assemelha-se aos arquivos oficiais e, como tal, do poder (NAMER, 1987, p.163).

A partir do renascimento, Namer (1987, p.164) acredita que as bibliotecas tenham passado a atuar como "memória do colecionador", o que nas bibliotecas públicas, em relação aos acervos doados, seria "memória dos doadores".

Em 1810, com o aparecimento da bibliografia da França, a biblioteca "permite o controle político sobre a produção", (NAMER 1987, p.162), o chamado depósito legal nas bibliotecas nacionais e, como atividade biblioteconômica, o controle bibliográfico.

Por um lado, a biblioteca é acumulação de memórias eruditas quando, por exemplo, guarda manuscritos e, por outro, é acumulação de memórias culturais se armazena a produção de uma determinada cultura.

Namer (1987.p.162-163) atribui à biblioteca o papel de unificadora de memórias coletivas culturais sucessivas, unificação que se efetiva interna e externamente, a primeira através de citações. $\mathrm{Na}$ "memória cultural livresca", como ele denominava, caberiam as citações, os dicionários de citações, as teses, manuais de referência, portanto, formas de memórias diversas e até opostas. Acrescentaríamos as bibliografias e repertórios e, hoje, as bibliotecas digitais e repositórios, como temos ressaltado neste texto. 
Uma das mais interessantes abordagens de Namer (1987, p.163) é das bibliotecas públicas, em que ele visualiza atribuições distintas das demais bibliotecas, "lembranças da afetividade de uma sociedade". Ele cita as bibliotecas públicas gregas, fundadas por Licurgo, "não somente o acúmulo do saber estético, das belas formas literárias... querem ser a 'medicina das almas' porque conservam, assim, os meios de recriar, por meio do teatro, os momentos vividos de afetividade coletiva intensa"

Namer (1987, p.163) novamente recorre a Halbwachs, no seu entendimento de partitura musical como memória coletiva, para exemplificar o trabalho de uma biblioteca nacional ou de departamento de música, ao reunir partituras musicais, considerando o concerto "uma prática institucional de memória cultural" que, como muitas outras, acontecem graças às bibliotecas, embora os consertos não sejam realizados nos espaços da biblioteca.

$\mathrm{Na}$ compreensão de Namer (1987, p.164), as bibliotecas desempenham, inclusive o papel de "memória lembrança de língua", por serem sistemas de difusão, memória social que é também memória mensagem. Esta ideia pode ser relacionada, modernamente, às comunidades discursivas e à teoria da mensagem, de Rafael Capurro (Angelética).

Além dessas formas, as bibliotecas trazem, dentro de si, a "memória de difusão", esta, pelas cópias, e a memória de patrimônio nacional. Os serviços e produtos de informação, as fontes secundárias, como as bibliografias, ao desempenharem a ação de disseminar, cumprem esse papel.

No contexto das bibliotecas, os bibliotecários constroem "memória administrativa", assunto ao qual Namer (1987, p.166) dedica parte do capítulo. Os bibliotecários assumem o papel de guardiões porque selecionam, guardam, acumulam, com base em regras. Desempenham, ainda, o papel de mediadores, junto aos leitores, uma vez que decodificam a linguagem dos leitores e a transpõem para o 
código da biblioteca. $\mathrm{O}$ autor se estende em considerações sobre as atividades de bibliotecários, nas suas relações com a memória, aqui enfocadas mais adiante.

Quais são, para Namer (1987, p.175), as práticas de memória livresca? Ele volta a recorrer a Halbwachs na sua fundamentação, utilizando-se de conceitos de memória diálogo e memória vivida para explicitar o seu pensamento: "a memória prévia, aquela do leitor interrogando o fichário, é unicamente uma memória diálogo. O conjunto da prática cognitiva é, antes de tudo, memória diálogo: as outras práticas são, antes de tudo, memória vivida; é o regulamento mesmo das bibliotecas que indica a hierarquia ou a coexistência dessas práticas".

A amplitude e o multifacetado pensamento de Namer, ao demarcar as inumeráveis memórias exercidas em bibliotecas, por sua vez de diferentes naturezas, são aqui expostos de forma sintética e com ênfase nos aspectos relacionados à temática deste artigo, portanto, estão longe de ser exaustivos e, menos ainda, esgotados. Além desse reconhecimento, é fundamental considerar, ainda, que as práticas de memória variam no tempo e de sociedade para sociedade, o que nos faz ressaltar a conclusão do autor de que "a sociologia do trabalho intelectual é um terreno inexplorado".

A partir daí, no próximo tópico abordaremos como chegam e se manifestam, no Brasil, as ideias e as iniciativas de Paul Otlet.

\section{DO INSTITUTO INTERNACIONAL DE BIBLIOGRAFIA - IIB AO INSTITUTO BRASILEIRO DE BIBLIOGRAFIA E DOCUMENTAÇÃO - IBBD}

Este tópico visa a investigar o quanto Otlet e suas ideias, inclusive as bibliografias, estão presentes no discurso e nas ações de bibliotecários, documentalistas e estudiosos de Ciência da Informação brasileiros. 
O pensamento de Paul Otlet foi trazido ao Brasil, no início do século 20, pelo então Diretor da Biblioteca Nacional, Cícero Peregrino da Silva, e influenciou a criação do Instituto Brasileiro de Bibliografia e Documentação-IBBD, atual IBICT.

O Instituto Internacional de Bibliografia - IIB, criado em 1895 por Otlet e La Fontaine, aparece refletido no próprio nome do Instituto (IBBD), fundado em 1954, e que antecede o hoje Instituto Brasileiro de Informação em Ciência e Tecnologia -IBICT, denominação alterada em 1976. O IBBD foi fundado por movimento externo e interno, uma vez que foi a UNESCO que estimulou a sua criação, em ação conjunta com a Fundação Getúlio Vargas - FGV, na ocasião detentora de um expressivo acervo de Ciências Sociais (PINHEIRO, 1997, p.83-84).

As iniciativas do IIB aparecem também nas principais atividades do IBBD, naquela fase, as bibliografias especializadas brasileiras, as buscas bibliográficas, o Cadastro de Pesquisas em Andamento e o Serviço de Intercâmbio de Catalogação - SIC, repassado pela FGV, além do Catálogo Coletivo Nacional de Publicações Seriadas-CCN e a reprodução de documentos (PINHEIRO, 1997, p. 84). O SIC já adotava o modelo cooperativo, que marcou muitos dos serviços de documentação de Otlet, como as cópias de fichas enviadas pela Library Congress, British Museum e até da Biblioteca Nacional brasileira para compor os catálogos do Repertório Bibliográfico Universal-RBU.

Tão importantes quanto esses serviços e produtos de informação foram as atividades de capacitação de recursos humanos, por meio do Curso de Especialização em Pesquisa Bibliográfica, oferecido desde o ano seguinte à fundação do Instituto, depois denominado Curso de Especialização em Documentação e Informação - CDC. Mais uma vez as ideias de Otlet aparecem, não somente por sua denominação, mas especialmente pela clientela que atendia, não limitada a bibliotecários, mas aberto também aqueles que desejassem trabalhar com documentos e informação em determinada área, ou melhor, documentalistas 
(PINHEIRO, 1997 p.90). A experiência com a especialização permitiu, 11 anos após, a criação do Mestrado em Ciência da Informação, implantado em 1970, pioneiro no Brasil e na América Latina. E até hoje recebendo alunos de mestrado e doutorado das várias regiões brasileiras e até de outros países, sobretudo da América Latina, característica desde o seu início e mantida até hoje.

Entre as manifestações de documentação e informação que traduzem a influência de Otlet, em nosso País, não pode deixar de ser destacada a tese de livre docente de Hagar Espanha Gomes (1975) sobre o pensamento do documentalista. Ela foi uma das primeiras diretoras do IBBD e professora do Programa de Pós-Graduação em Ciência da informação desde o seu início, hoje aposentada mas sempre participativa nas atividades acadêmicas e de pesquisa.

A professora Hagar é também coordenadora do Portal BITI Biblioteconomia, Informação e Tecnologia da Informação (http://www.conexaorio.com/biti/), constituído pelos seguintes pontos de acesso: artigos e manuais, livros on line e teses e dissertações. A temática predominante é a organização do conhecimento, especialmente tesauros, terminologia, classificação, além de livros de documentalistas clássicos, como o famoso "Qu'es-ce que la documentation?", de Suzane Briet, reproduzido no portal. A própria professora Hagar traduziu e publicou, entre outros, "Documentos e Documentação", de Paul Otlet, Introdução aos trabalhos do Congresso Mundial da Documentação Universal, realizado em Paris, em 1937.

A presença do pensamento de Otlet no Brasil pode ser também atestada pelo estudo sistemático de Paul Otlet, na disciplina Perspectivas da Ciência da informação, ministrada no Programa de PósGraduação em Ciência da Informação, do IBICT, em convênio com a 
UFRJ ${ }^{4}$. Consequentemente, tem sido geradas publicações, tendo por autores mestrandos ou doutorandos, entre as quais não pode deixar de ser citado o artigo de um mestrando do PPGCl, Helio Ferreira Jr., intitulado "Otlet realizador ou visionário? O que existe em um nome?", a partir de um artigo de Isabelle Rieusset-Lemariê. Às críticas dessa autora ao centralismo e positivismo de Otlet, Ferreira Jr. contrapõe a interdependência internacional pensada por ele e La Fontaine, posterior à primeira grande guerra, e os aspectos democráticos de sua obra. Ferreira Jr. dedica parte de seu artigo ao controle que Otlet pretendia, em relação à produção de conhecimento no mundo e faz menção ao panoptismo de Bentham, no século IX. Apoiado teoricamente em Arendt, Bobbio, Bourdieu e sobretudo Foucault, Ferreira Jr. conclui que Paul Otlet "era por seus atos e ideias, um cientista social permanentemente muito preocupado com o desenvolvimento do gênero humano e, em seu campo, seguirá sendo um revolucionário. No sentido mesmo daquele que enxerga muito além do seu tempo".

Outro indício da presença de Otlet é a coletânea organizada por Pereira e Pinheiro (2000), em homenagem ao grande documentalista, na qual constam alguns capítulos que direta ou indiretamente remetem a ele ou temas que estudou e, principalmente, pelo precioso prefácio elaborado por Pereira, uma síntese, podemos dizer, apaixonada das obras de Paul Otlet, (2000, p.vii-xxiv). Em alguns programas de PósGraduação em Ciência da Informação tem aparecido dissertações e teses, entre os quais nos programas da USP e da UNB, entre outros.

Instrumento de difusão das ideias de Otlet, o documentário "L’homme qui voulait classer le monde", de Françoise Levie, foi passado pela primeira vez no Brasil no IBICT, na Semana Nacional de Ciência e Tecnologia, no Rio de Janeiro, em 2006, e até hoje é regularmente

\footnotetext{
${ }^{4}$ A professora da disciplina, há mais de 15 anos, é a autora deste artigo, Lena Vania Ribeiro Pinheiro, a partir de 2015 a ministrando juntamente com o Professor Gustavo da Silva Saldanha.
} 
apresentado no Curso de Perspectivas da Ciência da Informação (PPGCI IBICT-UFRJ), já mencionado, tendo circulado entre vários professores e sido lançado para um público mais amplo, no ENANCIB, 2007, com a presença da diretora Françoise Levie.

Essas formas de disseminar a produção e ações de Paul Otlet tem continuidade e a cada ano conquistam um público maior e, consequentemente, novos estudiosos de sua obra.

\section{REFLEXÕES E REFLEXOS}

A presença de Paul Otlet no Brasil, apontada por iniciativas, ações e publicações em nosso País demonstra que, diferentemente do Estados Unidos, que concentra pesquisas e avanços em Ciência da Informação mas "descobriu" Otlet tardiamente, no final dos anos 1990, aqui Otlet vem sendo estudado desde a década de 1970. Certamente o fato de a Documentação ter se desenvolvido especialmente na França e as naturais dificuldades com a língua francesa, contribuíram para esse distanciamento e desconhecimento. Deve-se a W. Boyd Rayward, cientista da informação da Austrália, a difusão sistemática do pensamento e obras de Otlet pelo mundo e, nos Estados Unidos, a Michael Buckland, historiador da Ciência a Informação, que atualmente mantém um

portal (http://people.ischool.berkeley.edu/ buckland/otlet.html) sobre Otlet e foi editor, em 1998, juntamente com Hahan, de uma coletânea na qual o grande documentalista é estudado em alguns capítulos.

$\mathrm{O}$ engajamento de pesquisadores brasileiros em estudos sobre documentos e documentação, em manifestações do neodocumentalismo, reforça a afirmativa inicial sobre Otlet no Brasil, cujo exemplo significativo é a iniciativa do evento Seminário Internacional A Arte da Bibliografia, promovido pelo IBICT e pelo PPGCINF, da UnB, no qual foi conferencista Stephanie Manfroid, do Mundaneum, e quando foi primeiramente apresentado este estudo. 
No decorrer das leituras, ficou evidenciada a relevância das ideias de documentalistas históricos Suzanne Briet, Louise Noelle Malclès e principalmente o próprio Paul Otlet, por terem construído os alicerces teóricos, pela formulação de conceitos e a consistência de suas discussões.

O estudo das bibliografias, nas suas origens, estimulou a autora do presente artigo a ultrapassar as questões inicialmente pensadas e ir além como, por exemplo, a temática de bibliotecas e memória.

Os conceitos originais facilitam a compreensão dos termos no seu tempo e a sua passagem por mutações, especialmente decorrentes das transformações da sociedade e tecnologias de informação e comunicação. Problemas de tradução aparecem, sobretudo os relativos às denominações em francês para classificação (classement, classification e classer), sem correspondente específico em português, o que pode criar barreiras linguísticas, especificamente as de interlínguas, além das intralínguas.

Outro exercício estimulante foi traçar analogias entre serviços e produtos de informação dos primórdios da Documentação, entre os quais as bibliografias e repertórios, com os atuais repositórios, bibliotecas digitais e virtuais, em uma trajetória que chegou ao acesso livre / aberto à informação científica, aos dados de pesquisa ou dados científicos. Podemos pensar que os desejos democráticos de Otlet atingiram o seu ápice, com a abertura total e irrestrita da produção de conhecimento, aí incluídas as fontes primárias que embasam as pesquisas, embora o movimento da ciência aberta, em suas vertentes, possamos dizer, esteja apenas começando.

As múltiplas memórias que as bibliotecas contém e exercem em relação aos usuários, são estudadas por Namer, a partir dos conceitos de memória, especialmente a social, de Halbawchs, e podem ser correlacionadas a questões atuais que integram agenda de pesquisa da Ciência da Informação, no Brasil e no exterior, por exemplo, memória 
mensagem e a teoria da mensagem de Rafael Capurro, a Angelética e a abordagem hermenêutica.

Essas memórias, por sua vez, são indicadoras de uma tipologia de bibliotecas muito rica e cujos conteúdos definem o caráter da memória que constituem.

Mesmo os bibliotecários, analisados como mediadores e de acordo com as atividades que desempenham, proporcionam linhas de pesquisa diferenciadas em relação ao seu papel e das bibliotecas na sociedade.

As marcas e marcos de Paul Otlet no Brasil, além de atestarem muitos anos de estudos relativos ao eminente e revolucionário documentalista, apontam indícios da suas ideias e iniciativas em instituições, serviços e produtos de informação, povoando o cenário da Ciência da Informação brasileiro e demonstrando a vitalidade e atualidade das ideias de Otlet e sua influência.

\section{REFERÊNCIAS}

BORGES, Jorge Luís. O livro. In: . Cinco visões pessoais. Brasília: Ed. Universidade de Brasília, 1985. (Coleção Itinerárias, 17).

BRIET, Susanne. Qu'es-ce que la documentation? Paris: Édit- Éditions Documentaires Industrieles et Techiques, 1951. 48 p.

BUCKLAND, Michael. Paul Otlet. Disponível em: <http://people.ischool.berkeley.edu/ buckland/otlet.html>.

CHALHUB, Tania. Ações para implantação de repositórios institucionais em Universidades públicas no Estado do Rio de Janeiro. Informação \& Sociedade: Estudos, João Pessoa, v. 22, n. 2, p. 115-126, maio/ago. 2012.

DUVIGNAUD, JEAN. Prefácio. In: HALBWACHS, Maurice. A memória coletiva. São Paulo: Vértice, 1990. (Biblioteca Vértice. Sociologia e Política). 
EGAN, Margaret, SHERA, Jesse. Foundations of a theory of bibliography. Library Quarterly, v. 22, n. 2: p.125-137, 1952.

FERREIRA Jr, Hélio da Silva. Otlet: realizador ou visionário? O que existe em um nome? Ciência da Informação, v.35, n.2, 2006. Disponível em: <http://revista.ibict.br/ciinf/index.php/ciinf/article/view/823/662>.

FOSKETT, D.J. Alguns aspectos sociológicos dos sistemas formais de comunicação do conhecimento. Revista de Biblioteconomia. Brasília, v.1, n.1:p. 3-14, jan/jun 1973.

GOMES, Hagar Espanha. O pensamento de Paul Otlet e os princípios do UNISIST. Tese livre docência (Biblioteconomia), Universidade Federal Fluminense, UFF, 1975.

GOMES, Hagar Espanha. Portal BITI - Biblioteconomia, Informação e Tecnologia da Informação. Disponível em:

$<$ http://www.conexaorio.com/biti>.

GUINCHAT, Claire; AUBRET, Pierre. La documentation au service de l'action. Paris: Presses d'lle de France, 1977.125p.

HAHN, Trudi B.; BUCKLAND, Michel, eds. Historical studies in information Science. Softbound, 1998. 326p.

HALBWACHS, Maurice. A memória coletiva, São Paulo, Vértice. Ed. Revista do Tribunais, 1990. (Biblioteca Vértice. Sociologia e Política).

LEVIE, Françoise. L'homme qui voulait classer le monde: Paul Otlet et le Mundaneum ('The Man Who Wanted to Classify the World: Paul Otlet and the Mundaneum). Brussels: Les Impressions Nouvelles, 2006. Documentary

NAMER, Gérard. Les Institutions de memoire culturelle. In: Mémoire et Societé. Paris: Méridiens Klinckseck, 1987. p.158-185

OTLET, Paul. Traité de Documentation: le livre sur le livre. Théorie et pratique.Liège : Centre de Lecture Publique de la Communauté Française de Belgique, 1989. 432p.

PEREIRA, Maria de Nazaré Freitas. Prefácio. In: PEREIRA, Maria de Nazaré Freitas; PINHEIRO, Lena Vania Ribeiro (orgs). O sonho de Otlet: aventura em tecnologia da informação e comunicação. Rio de Janeiro, Brasília: IBICT/DEP/ DDI, 2000.

PEREIRA, Maria de Nazaré Freitas; PINHEIRO, Lena Vania Ribeiro (orgs). O sonho de Otlet: aventura em tecnologia da informação e comunicação. Rio de Janeiro, Brasília :IBICT/DEP/DDI, 2000. 
Do Instituto Internacional de Bibliografia ao Instituto Brasileiro de Bibliografia e Documentação: as bibliografias como memória do conhecimento e reflexos das ideias de Otlet no Brasil

PINHEIRO, Lena Vania Ribeiro. Ciência da Informação entre sombra e luz: domínio epistemológico e campo interdisciplinar. Rio de Janeiro: 1997. 278p. Tese(Comunicação e Cultura) UFRJ/ECO. Orientadora: Gilda Braga. Disponível em:

<http://biblioteca.ibict.br/phl8/anexos/lenavaniapinheiro 1997.pdf>.

SAYÃO, Luis Fernando; SALES, Luana Farias. Dados de pesquisa: contribuição para o estabelecimento de um modelo de curadoria digital para o país. Tendências da Pesquisa Brasileira em Ciência da Informação, v. 6, p. 1-26, 2013.

VERNANT, Jean Pierre. Mito e pensamento entre os gregos: estudos de psicologia história. São Paulo: DIFEL, Ed. da USP, 1973. 332 p.

\section{Title}

From the international institute of bibliography to Brazilian institute of bibliography and documentation: bibliographies as memory of knowledge and reflexes of Otlet's ideas in Brazil

\section{Abstract}

Introduction: The work investigate the initial concepts of bibliography devised by historic documentalists, the conceptualization of bibliographies as "a scientific method of research and classification" and the distinction between conceptualizing classification and the act of classifying, and the difficulties of translation (in French: classement, classer, classification).

Objective: To discuss the relationship between bibliographies and repertories and the current repositories.

Methodology: This is a theoretical work, structured from literature.

Results: perceives the bibliographies as memory of knowledge and in different approaches related to the activities carried on in libraries: message memory, traditional collective memory, cognitive memory, bookish cultural memory, dialogue memory, and live memory, among others.

Conclusions: identifies the reflexes of Paul Otlet's ideas and bibliographies in contemporary information actions, particularly in Brazil: the Brazilian Institute of Bibliography and Documentation currently IBICT- Brazilian Institute of Information in Science and Technology, the Course of Bibliographical Research, Brazilian publications, Brazilian studies and research.

Key words: Bibliography. Bibliographical concepts. Bibliography and memory. Otlet and his influence in Brazil. 
Lena Vania Ribeiro Pinheiro

Do Instituto Internacional de Bibliografia ao Instituto Brasileiro de Bibliografia e Documentação: as bibliografias como memória do conhecimento e reflexos das ideias de Otlet no Brasil

\section{Titulo}

Del instituto internacional de bibliografía al instituto brasileño de bibliografía y documentación: las bilbiografías como memória de conocimiento y reflejos de las ideas de Otlet en Brasil

\section{Resumen}

Introducción: El trabajo investiga los primeros conceptos de bibliografía formulados por documentalistas históricos, la concepción de bibliografías como "método científico de investigación y clasificación" y la distinción entre la concepción de una clasificación y el acto de clasificar, y dificultades de traducción (en francés: classement, classer, classification).

Objetivo: Discutir la relación la relación entre bibliografías y repertorios y los actuales repositorios.

Metodología: Se trata de un trabajo teórico, estructurada de la literatura.

Resultados: percibe las bibliografías como memoria del conocimiento y en distintos abordajes relacionados a las actividades en bibliotecas: memoria mensaje, memoria colectiva tradicional, memoria cognitiva, memoria cultural libresca, memoria diálogo y memoria vivida, entre otras.

Conclusiones: identifica los reflejos de las bibliografías y de las ideas de Paul Otlet en las acciones de información contemporáneas, especialmente en Brasil: el Instituto Brasileño de Bibliografía y Documentación actual IBICT- Instituto Brasileño de Información en Ciencia y Tecnología, el Curso de Investigaciones Bibliograficas, publicaciones, estudios y investigaciones brasileños.

Palabras clave: Bibliografía. Conceptos de bibliografia. Bibliografía y memoria. Otlet y suas ideas en Brasil

Recebido em: Abril de 2015

Aceito em: Julho de 2015 